\title{
Efeito do tratamento de sementes de algodoeiro com fungicidas no controle do tombamento de plântulas causado por Rhizoctonia solani, sob condições de casa de vegetação
}

\author{
Augusto César Pereira Goulart \\ Embrapa Agropecuária Oeste, 79804-970, Dourados, MS, Brasil \\ Autor para correspondência: Augusto C.P. Goulart, e-mail: goulart@cpao.embrapa.br
}

\begin{abstract}
RESUMO
O objetivo deste trabalho foi avaliar a eficácia do tratamento de sementes de algodoeiro com fungicidas no controle do tombamento de plântulas causado por Rhizoctonia solani. O ensaio foi conduzido na casa de vegetação da Embrapa Agropecuária Oeste, em Dourados, Mato Grosso do Sul. Sementes não tratadas e tratadas com os fungicidas foram semeadas em areia contida em bandejas plásticas, dispostas em orifícios individuais, eqüidistantes e a $3 \mathrm{~cm}$ de profundidade. A inoculação com $R$. solani AG-4 foi feita utilizando-se $5 \mathrm{~g}$ do inóculo do fungo/bandeja, distribuídos de forma homogênea na superfície do substrato. O fungo foi cultivado por 35 dias em sementes de aveia preta autoclavadas e trituradas em moinho $(1 \mathrm{~mm})$. Foi observado efeito significativo do tratamento fungicida na emergência inicial e final de plântulas, bem como no controle do tombamento de pré e pós-emergência do algodoeiro, com os melhores resultados sendo obtidos pelos tratamentos tolylfluanid+pencycuron+triadimenol e azoxystrobin+fludioxonil+mefenoxan, seguidos de carboxin+thiram, PCNB e pencycuron. O fungicida menos eficiente foi o carbendazim+thiram. Melhores resultados com relação às variáveis estudadas foram obtidos com a utilização de misturas de fungicidas em comparação ao uso isolado de um determinado produto. Não foram observadas diferenças significativas com relação ao índice de velocidade de emergência, altura e peso fresco das plântulas.
\end{abstract}

Palavras-chave: emergência de plântulas, inoculação, fungo.

\begin{abstract}
Effect of cotton seed treatment with fungicides in the control of Rhizoctonia solani seedling damping-off under greenhouse conditions

The objective of this work was to evaluate the efficacy of cotton seed treatment with fungicides in the control of $R$. solani seedling damping-off. This experiment was carried out under greenhouse conditions at Embrapa Agropecuária Oeste, in Dourados city, Mato Grosso do Sul State, Brazil. Treated and untreated seeds of the cultivar DeltaOpal were sowed in sand contained in plastic trays, placed in individual and equidistant wells, $3 \mathrm{~cm}$ deep. Into each plastic tray were put $5 \mathrm{~g}$ of the pathogen inoculum. The inoculation of $R$. solani AG-4 was done by the homogeneous distribution of the fungus inoculum onto the substrate. The fungus was grown for 35 days on autoclaved oat seeds and then ground to powder using a mill $(1 \mathrm{~mm})$. The evaluations were done based on symptoms development and seedling survival. The significant effect of the fungicide treatment on initial and final seedling emergence, as well as in the control of pre and post-emergence dampingoff was observed. The best results were obtained with tolylfluanid+pencycuron+triadimenol and azoxystrobin+fludioxonil + mefenoxan, followed by carboxin+thiram, PCNB and pencycuron. The least efficient fungicide was carbendazim+thiram. Seed treatment with fungicide combinations provided better results than the use of the single ones. No significant effect was observed in relation to speed of emergence index, seedling height and seedling fresh weight.
\end{abstract}

Keywords: seedling emergence, inoculation, fungus.

De todas as doenças que atacam o algodoeiro (Gossypium hirsutum L.), o tombamento é considerado uma das principais (Davis et al., 1997; Wang \& Davis, 1997; Goulart, 2001). Nas condições edafoclimáticas do Brasil, principalmente em se tratando do algodoeiro cultivado no cerrado, o principal agente causal do tombamento de plântulas é Rhizoctonia solani Kuhn grupo de anastomose (AG)-4 (teleomorfo: Thanatephorus cucumeris (A.B. Frank) Donk), pela freqüência que ocorre (mais de $95 \%$ dos casos) e pelos danos que causa na fase inicial de estabelecimento da lavoura (Goulart, 2001, 2002).

Este fungo ataca as sementes e plântulas de algodoeiro, ocasionando o tombamento de pré e pós emergência (Moustafa-Mahmoud et al., 1993). Porém é considerado mais prejudicial que os demais (Colletotrichum gossypii, $C$. gossypii var. cephalosporioides, Fusarium spp. e Pythium sp.) por causar, em maior intensidade, o tombamento de préemergência, conforme evidencia Sinclair (1965). Para se ter uma idéia da importância que esta doença assume nesse contexto, as perdas em produção devido à sua ocorrência são significativas. Segundo McLean \& Gazaway (2004), nos EUA, em 1995, estimou-se uma redução na produtividade do algodoeiro devido às doenças iniciais da ordem de 180.000 toneladas, sendo que nos últimos 10 anos, ainda nos EUA, 
estimativas de perdas têm revelado valores médios de 2,8\% ao ano. Até o momento, não foram levantados dados desta natureza no Brasil.

O controle das doenças do algodoeiro poderá ser obtido através do desenvolvimento de um sistema de Manejo Integrado, o qual baseia-se no princípio de manter a doença abaixo do limiar de dano econômico, sem prejuízo para o agroecossistema, utilizando medidas biológicas, culturais e químicas (Zambolim et al., 2000). Como parte integrante de uma agricultura sustentada, o Manejo Integrado de Doenças deverá agregar todas as táticas disponíveis de controle.

Dentre o conjunto de práticas recomendadas para o controle do tombamento, o tratamento das sementes com fungicidas tem sido, até o momento, a principal medida adotada e a opção mais econômica para minimizar os efeitos negativos dessa doença, conforme evidenciam Garber et al. (1980), Davis et al. (1997), Wang \& Davis (1997) e Goulart \& Melo Filho (2000).

A cada ano, um grande número de fungicidas são avaliados com o objetivo de verificar sua eficiência no controle do tombamento. De acordo com Garber et al. (1980), Davis et al. (1997) e Wang \& Davis (1997) o desempenho desses produtos depende da população desses fungos no solo, ou seja, é influenciado pela pressão de inóculo do patógeno no solo e também pelas interações com outros fungos, o que pode evidenciar um efeito supressivo. Igualmente, a suscetibilidade das cultivares e a cultura antecessora ao algodoeiro também poderão influenciar nos benefícios do tratamento de sementes com fungicidas. Entretanto, deve-se considerar que, até o momento, não se tem evidências de que o uso de fungicidas em tratamento de sementes com ação específica contra $R$. solani possa ser dispensado em áreas com histórico de ocorrência deste patógeno.

O objetivo deste trabalho foi avaliar a eficácia do tratamento de sementes de algodoeiro com fungicidas no controle do tombamento de plântulas causado por Rhizoctonia solani.

O ensaio foi conduzido em casa de vegetação da Embrapa Agropecuária Oeste, em Dourados MS. Para a produção de inóculo do patógeno, utilizou-se de metodologia descrita por Asmus et al. (1993) e Goulart et al. (2000). Culturas puras de $R$. solani AG-4, isolado de lesões do coleto de plântulas de algodoeiro, foram mantidas em meio de cultura BDA contido em placas de Petri previamente esterilizadas em Forno de Bier por 48 horas, em estufas de incubação para BOD, por 5 dias, sob fotoperíodo de 12 horas, a $22^{\circ} \mathrm{C}$, condições estas necessárias para o crescimento do patógeno. Após esse período, o fungo foi repicado para um substrato composto de $2 \mathrm{~kg}$ de sementes de aveia preta e $0,5 \mathrm{~L}$ de água, previamente autoclavado em Erlenmeyer de 2,0L, durante 30 minutos, por três dias consecutivos, a $127^{\circ} \mathrm{C}(1,5$ atm de pressão) sendo mantido sob condições ambientes por 35 dias. No $35^{\circ}$ dia, foi retirada do Erlenmeyer a aveia colonizada pelo fungo, a qual foi seca à sombra por dez dias. Ao final desse período, o substrato contendo o fungo foi triturado em um moinho $(1 \mathrm{~mm})$, de modo a se obter o inóculo do patógeno, na forma de um pó.

$\mathrm{O}$ tratamento fungicida foi realizado colocando-se os produtos sobre $500 \mathrm{~g}$ de sementes de algodoeiro da cultivar Delta Opal em sacos plásticos de 2,0L e agitando-se o recipiente por alguns minutos até a completa cobertura das mesmas pelos fungicidas.

As sementes deslintadas com ácido sulfúrico, tratadas e não tratadas com os fungicidas, foram semeadas em areia lavada, previamente autoclavada por três vezes consecutivas, sendo cada autoclavagem por 3 horas a $127^{\circ} \mathrm{C}$ com $1,5 \mathrm{~atm}$ de pressão e contida em bandejas plásticas $(56 \times 35 \times 10 \mathrm{~cm})$. As sementes foram distribuídas em orifícios individuais, eqüidistantes e a $3 \mathrm{~cm}$ de profundidade. Antes do fechamento dos orifícios, foi feita a inoculação com $R$. solani. Uma quantidade pré estabelecida do inóculo do patógeno $(5 \mathrm{~g} /$ bandeja) foi misturada a $1 \mathrm{~kg}$ de areia, sendo esta mistura distribuída homogeneamente na superfície do substrato, de modo a cobrir todas as sementes e ficar em contato direto com as mesmas.

Para as avaliações de emergência inicial e final e de tombamento de pré e pós-emergência, foi utilizado o teste de emergência em areia (growing on test). Para cada bandeja plástica contendo areia lavada, foram semeadas 200 sementes. Foram realizadas duas avaliações de emergência: a avaliação inicial (aos sete dias após a semeadura - 7 DAS) e a avaliação final (aos 26 DAS). A avaliação de tombamento foi realizada diariamente, a partir dos 7 DAS, registrando o número de plântulas tombadas até os 26 DAS. Ao final desse período obteve-se um valor final cumulativo de plântulas tombadas. Para a confirmação do patógeno, plântulas com sintomas de tombamento foram coletadas, lavadas em água corrente, desinfestadas superficialmente com uma solução de hipoclorito de sódio a $1,5 \%$ por 3 minutos e posteriormente submetidas à câmara úmida. Após cinco dias de incubação em estufas para $\mathrm{BOD}$, a $22^{\circ} \mathrm{C}$ e $12 \mathrm{~h}$ luz $/ 12 \mathrm{~h}$ escuro, foi realizado o exame e identificação do patógeno. Avaliou-se ainda o índice de velocidade de emergência (IVE), que foi determinado segundo a fórmula: I.V.E $=\mathrm{E} 1 / \mathrm{N} 1+\mathrm{E} 2 / \mathrm{N} 2+\mathrm{Em} / \mathrm{Nn}$, sendo E1, E2, En = o número de plântulas normais na primeira, segunda e na ultima contagem e, N1, N2, Nn = números de dias de semeadura à primeira, segunda e ultima contagem, em conjunto com o teste de emergência em areia (Maguire, 1962). No último dia do teste de emergência foram efetuadas ainda as determinações de altura $(\mathrm{cm})$ e peso fresco das plântulas $(\mathrm{g})$.

Utilizou-se o delineamento experimental inteiramente casualizado, com oito tratamentos e quatro repetições. Para a análise de variância, os dados de percentagem foram transformados para arc sen $\sqrt{x / 100}$. As médias foram comparadas pelo teste de Duncan, ao nível de 5\% de probabilidade.

Para garantir que os resultados revelassem única e exclusivamente o efeito do fungo $R$. solani sobre a emergência e tombamento, foram utilizadas sementes livres de qualquer espécie de fungo (escolha baseada em resultados de vários testes de sanidade de sementes) que pudessem interferir nas avaliações. 
A emergência inicial e final bem como o tombamento de pré e pós-emergência de plântulas de algodoeiro causado por $R$. solani foram significativamente influenciados pelo efeito do fungicida (Tabela 1), sendo mais eficazes os tratamentos tolylfluanid+pencycuron+triadimenol e azox ystrobin+fludioxonil+mefenoxan, os quais não diferiram estatisticamente entre si, seguidos de carboxin+thiram, PCNB e pencycuron. O tratamento carbendazim+thiram foi significativamente inferior, proporcionando menores percentagens de plântulas emergidas e níveis mais baixos de controle do tombamento de plântulas de algodoeiro em comparação aos tratamentos mais eficientes.

Não foram observadas diferenças significativas entre os tratamentos fungicidas e as testemunhas com relação ao índice de velocidade de emergência, altura de plântulas e peso fresco de plântulas (Tabela 2).

O fungo $R$. solani pode causar tombamento de pré e pós-emergência, o que foi observado nas condições do presente ensaio. A avaliação da percentagem de emergência final de plântulas (26 DAS), reflete a eficiência dos fungicidas na proteção das mesmas contra o ataque de $R$. solani, bem como a capacidade de manutenção do estande, no sentido de evitar o tombamento de pós-emergência causado por este patógeno. O efeito drástico do patógeno pode ser observado quando se comparam os resultados obtidos nas testemunhas com e sem inoculação.

Os resultados observados demonstraram a fitocompatibilidade com o algodoeiro de todos os fungicidas

TABELA 1 - Emergência inicial e final e tombamento de pré e pós-emergência causado por Rhizoctonia solani em função dos diferentes tratamentos fungicidas aplicados às sementes de algodoeiro. Embrapa Agropecuária Oeste.

\begin{tabular}{|c|c|c|c|c|c|}
\hline \multirow[t]{2}{*}{ Tratamentos } & \multirow{2}{*}{$\begin{array}{c}\text { Dose } \\
\text { a./100kg } \\
\text { De } \\
\text { sementes }\end{array}$} & \multicolumn{2}{|c|}{$\begin{array}{c}\text { Emergência de plântulas } \\
(\%)\end{array}$} & \multicolumn{2}{|c|}{\begin{tabular}{l}
\multicolumn{2}{l}{ Tombamento de } \\
plântulas $(\%)$
\end{tabular}} \\
\hline & & Inicial & Final & $\begin{array}{c}\text { Pré- } \\
\text { emergência }\end{array}$ & $\begin{array}{c}\text { Pós- } \\
\text { emergência }\end{array}$ \\
\hline Tolylfluanid+pencycuron+triadimenol & $100+75+40$ & $90,0 \mathrm{a}$ & $88,5 \mathrm{~b}$ & $2,2 \mathrm{e}$ & $1,7 \mathrm{~d}$ \\
\hline Azoxystrobin+fludioxonil + mefenoxan & $30+5+15$ & 90,0 a & $88,0 \mathrm{~b}$ & $2,2 \mathrm{e}$ & $2,2 \mathrm{~d}$ \\
\hline Carboxin+thiram & $140+140$ & 89,0 a & $83,0 \mathrm{c}$ & $3,4 \mathrm{~d}$ & $6,7 \mathrm{c}$ \\
\hline PCNB & 250 & 89,0 a & $82,5 \mathrm{c}$ & $3,4 \mathrm{~d}$ & $7,3 \mathrm{c}$ \\
\hline Pencycuron & 75 & 88,0 a & $82,0 \mathrm{c}$ & $4,3 \mathrm{c}$ & $6,8 \mathrm{c}$ \\
\hline Carbendazim + thiram & $90+210$ & $75,0 \mathrm{~b}$ & $66,5 \mathrm{~d}$ & $18,9 \mathrm{~b}$ & $11,3 \mathrm{~b}$ \\
\hline Testemunha não inoculada & - & $92,0 \mathrm{a}$ & $92,0 \mathrm{a}$ & $0,0 \mathrm{f}$ & $0,0 \mathrm{e}$ \\
\hline Testemunha inoculada & - & $47,0 \mathrm{c}$ & $29,5 \mathrm{e}$ & $49,2 \mathrm{a}$ & $37,2 \mathrm{a}$ \\
\hline Média & - & 82,50 & 76,50 & 10,42 & 9,15 \\
\hline C.V. $(\%)$ & - & 10,31 & 9,08 & 15,82 & 16,40 \\
\hline
\end{tabular}

Médias seguidas de mesma letra na coluna não diferem significativamente entre si. (Duncan, $5 \%$ ).

TABELA 2 - Índice de velocidade de emergência (IVE), altura $(\mathrm{cm})$ e peso fresco de plântulas $(\mathrm{g})$ em função dos diferentes tratamentos fungicidas aplicados às sementes de algodoeiro. Embrapa Agropecuária Oeste.

\begin{tabular}{lcccc}
\hline \hline Tratamentos & $\begin{array}{c}\text { Dose } \\
\text { i.a./100kg } \\
\text { de sementes }\end{array}$ & $\begin{array}{c}\text { Índice de } \\
\text { velocidade de } \\
\text { emergência }\end{array}$ & $\begin{array}{c}\text { Altura } \\
\text { de } \\
\text { plântulas (cm) }\end{array}$ & Peso fresco de \\
plântulas (g)
\end{tabular}

n.s. = não significativo 
Efeito do tratamento de sementes de algodoeiro com fungicidas...

utilizados, não sendo observados quaisquer tipos de sintomas nas plântulas que revelassem a presença de efeitos fitotóxicos advindos da utilização desses produtos, tais como aparecimento de plântulas com folhas deformadas e retorcidas ou até mesmo atraso na emergência. Relacionado a esse último aspecto, deve-se considerar que a semeadura foi realizada em condições ideais de temperatura e umidade do solo e também numa profundidade adequada ( 3 a $5 \mathrm{~cm}$ ). Os melhores resultados com relação às variáveis estudadas foram obtidos com a utilização de misturas de fungicidas (à exceção do tratamento carbendazim+thiram) em comparação ao uso isolado de um determinado produto, o que também pode ser observado na Tabela 1. Deve-se ressaltar que a ação combinada de fungicidas com diferentes espectros de ação tem sido uma estratégia eficaz no controle de maior número de patógenos presentes nas sementes e/ou no solo, além de evitar, em grande parte, o surgimento de populações resistentes entre os patógenos. Desse modo, a utilização de misturas de fungicidas, garante aos produtores maior segurança na semeadura para a obtenção de um estande ideal de plantas, nas mais variadas situações. Os resultados obtidos neste ensaio corroboram aqueles obtidos anteriormente por Asmus et al. (1993), Menten \& Paradela (1996), Goulart et al. (2000) e Goulart (2002).

Conforme DeVay et al. (1980), estudos em casa de vegetação, visando determinar a performance de fungicidas aplicados em tratamento de sementes de algodoeiro, tem sido um indicador bastante útil para predizer a eficácia desses produtos sob condições de campo. Diversos autores têm desenvolvido trabalhos dessa natureza em casa de vegetação, como, por exemplo, Asmus et al. (1993) e Goulart et al. (2000), que utilizaram esta mesma metodologia de inoculação de $R$. solani, além de Wang \& Davis (1997), que trabalharam com uma mistura de areia:turfa inoculada com $R$. solani e Menten \& Paradela (1996), que utilizaram solo inoculado com $R$. solani, através da distribuição de sementes de trigo autoclavadas e colonizadas pelo fungo. Os resultados deste trabalho, somados a estes citados anteriormente, demonstram a exequibilidade desse método de inoculação do substrato com $R$. solani, para avaliar a eficiência do tratamento de sementes de algodoeiro com fungicidas no controle desse patógeno, em condições de casa de vegetação. Esse tipo de trabalho proporciona resultados altamente confiáveis, uma vez que se trabalha em condições controladas, com quantidades e pressões de inóculo preestabelecidos, que permitem avaliar com precisão e praticamente sem chances de escape os benefícios do tratamento de sementes com fungicidas.

O tratamento de sementes de algodoeiro deve ser considerado como uma das alternativas mais eficazes para o controle do tombamento nessa cultura, vindo ao encontro à necessidade de se racionalizar o uso de produtos químicos na agricultura. Julga-se oportuno salientar que, principalmente quando se trata da cultura do algodoeiro, o tratamento de sementes com fungicidas se faz necessário e até mesmo indispensável, não se tendo evidências, até o momento, de que o uso desta prática com ação específica contra $R$. solani possa ser dispensada em áreas com histórico de ocorrência deste patógeno.

\section{REFERÊNCIAS BIBLIOGRÁFICAS}

Asmus GL, Goulart ACP, Paiva FA (1993) Eficiência de alguns fungicidas usados em tratamento de sementes de algodoeiro no controle do tombamento causado por Rhizoctonia solani. Fitopatologia Brasileira 18(Supl.):298.

Davis RM, Nunez JJ, Subbarao KV (1997) Benefits of cotton seed treatments for the control of seedling diseases in relation to inoculum densities of Pythium species and Rhizoctonia solani. Plant Disease 81:766-768.

Devay JE, Garber RH, Wakeman RJ (1980) Cotton seedling responses in greenhouse tests to combinations of chemical seed treatment for control of Pythium ultimum, Rhizoctonia solani, and Thielaviopsis basicola. Proceedings, Beltwide Cotton Production Research Conference. p. 19.

Garber RH, Devay JE, Weinhold AR, Wakeman RJ (1980) Pathogen inoculum a key factor in fungicide seed treatment efficiency. Proceedings, Beltwide Cotton Producion Research Conference.

Goulart ACP, Andrade PJM, Borges EP (2000) Controle do tombamento de plântulas do algodoeiro causado por Rhizoctonia solani pelo tratamento de sementes com fungicidas. Summa Phytopathologica 26:362-368.

Goulart ACP, Melo Filho GA (2000) Quanto custa tratar as sementes de soja, milho e algodoeiro com fungicidas? Dourados MS. Embrapa Agropecuária Oeste. Boletim de Pesquisa no. 7.

Goulart ACP (2001) Tratamento de sementes do algodoeiro com fungicidas. In: Algodoeiro: tecnologia de produção. Dourados MS, Embrapa Agropecuária do Oeste e Campina Grande PB, Embrapa Algodão. pp. 140-158.

Goulart ACP (2002) Efeito do tratamento de sementes de algodoeiro com fungicidas no controle do tombamento de plântulas causado por Rhizoctonia solani. Fitopatologia Brasileira 27:399-402.

Maguire JD (1962) Speeds of germination-aid detection and evaluation for seedling emergence and vigor. Crop Science 2:176177.

McLean K, Gazaway W (2000) Fungicides are worth the money: cotton seed disease management studies show fungicide use is effective for Alabama farmers. Highlights of Agricultural Research, Auburn, v. 47, n. 2, Summer 2000. Disponível em: http://ag.auburn. edu/aaes/communications/highlights/summer00/fungicides.html. Acesso em: 14 out. 2004.

Menten JOM, Paradela AL (1996) Tratamento químico de sementes de algodoeiro para controle de Rhizoctonia solani. Summa Phytopathologica 22:60. (Resumo)

Moustafa-Mahmoud SM, Sumner DR, Ragab MM, Ragab MM (1993) Interaction of fungicides, herbicides, and planting date with seedling disease of cotton caused by Rhizoctonia solani AG-4. Plant Disease 77:79-86

Sinclair JB (1965) Cotton seedling diseases and their control. Baton 
A.C.P. Goulart

Rouge LA. Louisiana State University.

Wang H, Davis RM (1997) Susceptibility of selected cotton cultivars to seedling disease pathogens and benefits of chemical seed treatments. Plant Disease 18:1085-1088.

Zambolim L, Casa RT, Reis EM (2000) Sistema plantio direto e doenças em plantas. Fitopatologia Brasileira 25:585-595. 